\title{
EFFECT OF INTENSIVE COOLING OF ALLOY AZ91 WITH A CHROMIUM ADDITION ON THE MICROSTRUCTURE AND MECHANICAL PROPERTIES OF THE CASTING
}

\begin{abstract}
The work presents the results of the investigations of the effect of intensive cooling of alloy AZ91 with an addition of chromium on the microstructure and mechanical properties of the obtained casts. The experimental castings were made in ceramic moulds preliminarily heated to $180^{\circ} \mathrm{C}$, into which alloy AZ91 with the addition was poured. Within the implementation of the research, a comparison was made of the microstructure and mechanical properties of the castings obtained in ceramic moulds cooled at room temperature and the ones intensively cooled in a cooling liquid. The kinetics and dynamics as well as the thermal effects recorded by the TDA method were compared. Metallographic tests were performed with the use of an optical microscope and the strength properties of the obtained castings were examined: UTS (Rm), elongation (A\%), and HB hardness.

Keywords: investment casting technology, magnesium alloys, crystallization, TDA method, intensive cooling
\end{abstract}

\section{Introduction}

The world trends in the transport industry are aiming at reducing fuel consumption, which is very significant from the point of view of ecology as well as economy. As a result of these pursuits, new materials for vehicle parts are being searched for, which would characterize in a relatively low mass, at the same time preserving their high mechanical properties. In the recent years, high interest has been raised by magnesium alloys [1], which exhibit a relatively low density, owing to which the castings obtained from these alloys characterize in a low mass. Unfortunately, these alloys possess insufficient mechanical properties as compared with the commonly applied materials.

In order to improve their mechanical properties, magnesium alloys are enriched with various alloy additions $[2-9,16]$, including rare earth elements $[10,11]$. In the recent years, research has been conducted, which confirms that a small amount of chromium and/or vanadium improves the properties of magnesium alloys [12]. With the purpose to improve the mechanical properties of these alloys, new technologies are being elaborated, which characterize in directional solidification $[13,14]$ or rapid crystallization caused by intensive cooling of the ceramic moulds [15]. The most popular technologies used to obtain titanium and aluminum castings are: SOPHIA ${ }^{\circledR}[16,18]$ and HERO Premium Casting ${ }^{\circledR}[17,18]$.

The aim of this study is to examine the effect of intensive cooling of alloy AZ91 with $\mathrm{Cr}$ additions on the microstructure, mechanical properties and hardness $\mathrm{HB}$ of the experimental castings made in ceramic moulds intensively cooled in a cooling liquid. The obtained results of the tests on castings intensively cooled in a cooling liquid were compared with the ones for castings cooled at room temperature.

\section{Test methodology}

The research were performed on alloy AZ91 with the addition of $0.1 \mathrm{wt}$ \% $\mathrm{Cr}$. The chemical composition of the initial alloy AZ91 is presented in Table 1.

TABLE 1

Chemical composition of alloy AZ91

\begin{tabular}{|c|c|c|c|c|c|c|c|}
\hline \hline \multicolumn{7}{|c|}{ Element content, wt. \% } \\
\hline $\mathbf{M g}$ & $\mathbf{A l}$ & $\mathbf{Z n}$ & $\mathbf{M n}$ & $\mathbf{S i}$ & $\mathbf{F e}$ & $\mathbf{C u}$ & $\mathbf{N i}$ \\
\hline 90.027 & 9 & 0.8 & 0.1 & 0.05 & 0.004 & 0.008 & 0.001 \\
\hline
\end{tabular}

The alloy, according to the calculated burden, was enriched with an AlCr15 master alloy, whose chemical composition is presented in Table 2.

TABLE 2

Chemical composition of master alloy $\mathrm{AlCr} 15$

\begin{tabular}{|c|c|c|c|c|c|c|c|c|c|}
\hline \hline \multicolumn{10}{|c|}{ Element content, wt. \% } \\
\hline Mg & Al & Zn & Mn & Si & Fe & Cu & Ni & Cr & Other - max. \\
\hline 0.01 & 85.21 & 0.02 & 0.01 & 0.08 & 0.25 & 0.01 & 0.01 & 14.2 & 0.2 \\
\hline
\end{tabular}

\footnotetext{
* LODZ UNIVERSITY OF TECHNOLOGY, DEPARTMENT OF MATERIALS ENGINEERING AND PRODUCTION SYSTEMS, STEFANOWSKIEGO 1/15, 90-924 ŁÓDŹ, POLAND

Corresponding author: cezary.rapiejko@p.lodz.pl
} 
The alloy was melted in a laboratory crucible furnace with the capacity of $5 \mathrm{~kg}$, in a steel crucible made of steel S235JRG2 (PN-EN 10025-2:2007). Inside the furnace, a protective gas atmosphere was used, consisting of a mixture of $\mathrm{Ar}+\mathrm{SF}_{6}$ under the pressure of $0.15-0.20 \mathrm{MPa}$. The gas flow equaled: $10 \mathrm{~cm}^{3} / \mathrm{min}$ for $\mathrm{SF}_{6}$ and $500 \mathrm{~cm}^{3} / \mathrm{min}$ for Ar. Due to the high tendency of the introduced alloy addition for gravitational segregation, the magnesium alloy with the additions was intensively mixed in the crucible.

The cylinder casting samples for strength tests were prepared in ceramic moulds made according to the investment casting technology. The prepared ceramic mould is presented in Figure 1.

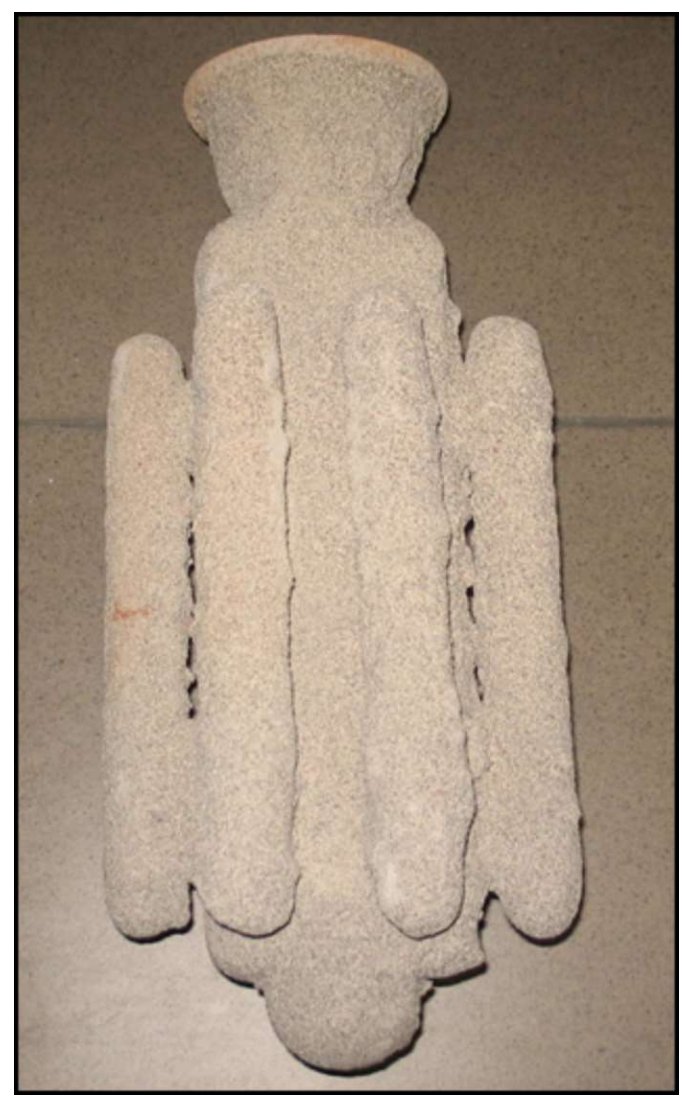

Fig. 1. Ceramic mould for strength test of castings

The moulds were made from refractory materials Refracoarse (flour and sands). The configuration of the coatings and the types of the materials applied for the preparation of the ceramic moulds have been presented in the study [19].

The moulds were fired at $960^{\circ} \mathrm{C}$ in a tunnel furnace, for their reinforcement. After the firing, the ceramic moulds were cooled to $180^{\circ} \mathrm{C}$, and next filled with liquid metal of the temperature of $740^{\circ} \mathrm{C} \pm 5^{\circ} \mathrm{C}$.

The moulds filled with the liquid metal, after the solidification of about $30 \%$ of the casting volume in a random microvolume of the cast, were submerged in a cooling agent at the rate of $V=0.08 \mathrm{~m} / \mathrm{s}$. The cooling agent used in the tests was a $20 \%$ solution of Polihartenol E8 in water, with the room temperature $t_{r}=20^{\circ} \mathrm{C}$. The solidification time of $30 \%$ of the casting volume in a random micro-volume of the casting was determined based on the performed simulation with the use of the Magma5 program. In the program, with the purpose of a correct simulation, the properties of magnesium alloys were defined on the basis of the data from the Magma5 system database:

- magnesium alloy AZ91,

- time of casting the metal in the mould: $4 \mathrm{~s}$,

- temperature of the liquid metal before ppouring casting: $740^{\circ} \mathrm{C}$,

- mould made of aluminium oxide base: $\mathrm{Al}_{2} \mathrm{O}_{3}$,

- temperature of the ceramic mould: $180^{\circ} \mathrm{C}$.

After the casting, the moulds which had been cooling down at room temperature, were placed on the cooling station.

The examinations of the process of solidification and crystallization of alloy AZ91 with alloy additions were performed in especially designed and constructed ceramic testers TDA10C-PŁ with the use of the TDA method. The construction of the testers and a diagram of the test station for the TDA method in the case of alloys cooling down at room temperature as well as the microstructures of the examined alloys AM60 and AZ91 have been presented in the study [20]. A diagram of the test station for the TDA method in the case of alloys intensively cooled in a cooling agent have been described in the study [15].

Evaluation was performed with the use of the TDA method of the following thermal crystallization processes: solidification $(t=f(\tau))$, kinetics $\left(d t / d \tau=f^{\prime}(\tau)\right)$ and dynamics $\left(d^{2} t / d \tau^{2}=f^{\prime \prime}(\tau)\right)$. On the derivation curve $d t / d \tau=f^{\prime}(\tau)$, the characteristic points were determined, which were then used to determine the thermal crystallization effects for the selected alloy:

A-D - crystallization of primary phase $\alpha_{\mathrm{Mg}}\left(\mathrm{L} \rightarrow \mathrm{L}+\alpha_{\mathrm{Mg}}\right)$, D-E-F-I - crystallization of eutectic $\alpha_{\mathrm{Mg}}+\gamma\left(\mathrm{Mg}_{17} \mathrm{Al}_{12}\right)$ $\left(\mathrm{L} \rightarrow \alpha_{\mathrm{Mg}}+\gamma\left(\mathrm{Mg}_{17} \mathrm{Al}_{12}\right)\right)$.

For a description of the characteristic thermal processes taking place during primary crystallization, the values determined for the characteristic points were applied:

- temperature of the alloy $t,\left[{ }^{\circ} \mathrm{C}\right]$,

- $\quad$ value of the first derivative of temperature after time $d t / d \tau$, $\left[{ }^{\circ} \mathrm{C} / \mathrm{s}\right]$,

- time $\tau$ from the beginning of measurement up to the moment when a characteristic point was recorded on the derivation curve $(d t / d \tau)$, [s],

- tangent value of the straight line inclination angle on the interpolated segment between the characteristic points $Z=\operatorname{tg}(\alpha) \approx d^{2} t / d \tau^{2},\left[{ }^{\circ} \mathrm{C} / \mathrm{s}^{2}\right]$.

In order to make visible the particular phases in the microstructure, the microsections were etched in a reagent of the following composition: $1 \mathrm{ml}$ acetic acid, $50 \mathrm{ml}$ distilled water and $150 \mathrm{ml}$ ethyl alcohol [21]. The microstructure of the examined alloys was observed by means of the optical microscope Nikon Eclipse MA200.

The examinations of the selected mechanical properties: ultimate tensile strength UTS $\left(R_{m}\right)$, elongation $A_{\%}$ were performed for samples rolled out of cylinder casts, according to the standard EN-ISO 6892/1, on the testing machine Instron 4485. The hardness measurements were conducted by the Brinell method, 
by way of determining the hardness HB with the loading force $F=490 \mathrm{~N}$, the penetrator (globule) diameter $d=2.5 \mathrm{~mm}$ and the load factor $k=10$.

\section{Description of results}

\section{a. Microstructure of alloy AZ91 with $\mathrm{Cr}$ additions cooling down at room temperature and intensively cooled}

Figure 2a,b shows the microstructure of alloy AZ91 with chromium additions, cooling in a ceramic mould at room temperature. The alloy microstructure consists of the phases: $\alpha_{\mathrm{Mg}}+$ eutectic $\left(\alpha_{\mathrm{Mg}}+\gamma\left(\mathrm{Mg}_{17} \mathrm{Al}_{12}\right)\right)$ and a phase formed from the introduced $\mathrm{AlCr}_{2}$ addition.

A very strong effect on the alloy microstructure in the casting being free of porosity defects - caused by the penetration of the ceramic mould by water vapour - is exerted by the participation of a solid phase in the casting at the moment when intensive cooling of the mould begins. The performed simulation of the process of filling the ceramic mould and solidification of the alloy performed with the use of the MAGMA5 program, as well as the validation of the simulation results under laboratory conditions, made it possible to determine the time needed from the moment of filling the mould to the beginning of its submerging in the cooling agent. This time is necessary for the formation of a layer, solidified in the volume of the mould shaping the cast, which is strong enough to resist the partial pressure of the gases trying to reach the liquid alloy. Based on these tests, it was assumed that the formation of a $30 \%$ solid phase in the alloy, in the area of the mould shaping the cast, makes it possible to obtain cylinder castings without defects caused by porosity

Figure $3 \mathrm{a}, \mathrm{b}$ show the simulation results for: the temperature distribution of alloy AZ91 after filling the mould for cylinder castings (a), the percentage of the solid phase in the volume of the casting made from alloy AZ91 (b). One can infer from the presented simulation of the temperature distribution of a cylin- der casting right after the filling of the moulds (Fig. 3a) that the coolest areas of the casting are its edges. In these areas, the liquid alloy has the temperature within the range of $660.8-653.6^{\circ} \mathrm{C}$. In the volume of the cylinder cast, after $20.5 \mathrm{~s}$ from the moment of casting (3b), large areas with an about $30 \%$ solid phase in the casting volume were observed.

Figure 4a,b shows the microstructure of alloy AZ91 with a chromium addition which was intensively cooled in the ceramic mould at room temperature. The alloy microstructure consists of the phases: $\alpha_{\mathrm{Mg}}+$ eutectic $\left(\alpha_{\mathrm{Mg}}+\gamma\left(\mathrm{Mg}_{17} \mathrm{Al}_{12}\right)\right)$ and $\mathrm{AlCr}_{2}$ originating from the introduced alloy addition.

\section{b. TDA analysis}

Figure 5 shows the TDA characteristics of alloy AZ91 with a chromium addition, solidifying in a ceramic TDA tester at room temperature and intensively cooled in a $20 \%$ water solution of Polihartenol E8.

Tables 3 and 4 present the compilations $\left(t, d t / d \tau, d^{2} t / d \tau^{2}\right)$ determined for the characteristic points, or segments determined by these points $\left(Z \approx d^{2} t / d \tau^{2}\right.$ ), from the TDA curves for the examined alloys.

TABLE 3

Characteristic TDA points and their corresponding values: $t=f(\tau)$, $d t / d \tau=f^{\prime}(\tau), d^{2} t / d \tau^{2}=f^{\prime \prime}(\tau), \mathrm{Z} \approx\left(d^{2} t / d \tau^{2}\right) \cdot 10^{-3}$ for alloy AZ91 with a chromium addition, cooling in the TDA10C-PŁ tester at room temperature

\begin{tabular}{|c|c|c|c|c|c|}
\hline \hline Point & $\begin{array}{c}\boldsymbol{\tau} \\
{[\mathbf{s}]}\end{array}$ & $\begin{array}{c}\boldsymbol{T} \\
{\left[{ }^{\circ} \mathbf{C}\right]}\end{array}$ & $\begin{array}{c}\boldsymbol{d} \boldsymbol{t} / \boldsymbol{d} \boldsymbol{\tau} \\
{\left[{ }^{\circ} \mathbf{C} / \mathbf{s}\right]}\end{array}$ & $\begin{array}{c}\boldsymbol{d}^{\mathbf{2}} \boldsymbol{t} / \boldsymbol{d} \boldsymbol{\tau}^{\mathbf{2}} \\
{\left[{ }^{\circ} \mathbf{C} / \mathbf{s}^{\mathbf{2}}\right]}\end{array}$ & $\begin{array}{c}\boldsymbol{Z} \approx \boldsymbol{d}^{\mathbf{2}} \boldsymbol{t} / \boldsymbol{d} \boldsymbol{\tau}^{\mathbf{2}} \cdot \mathbf{1 0}^{-\mathbf{3}} \\
{\left[{ }^{\circ} \mathbf{C} / \mathbf{s}^{\mathbf{2}}\right]}\end{array}$ \\
\hline A & 43.52 & 653.629 & -7.8508 & -3.522490357 & 576.69 \\
\hline B & 56.96 & 601.279 & -0.2373 & 0.228663597 & 144.17 \\
\hline D & 174.72 & 510.092 & -0.8377 & 0.000194035 & -10.43 \\
\hline E & 256.64 & 447.522 & -0.6976 & 0.002485976 & 3.85 \\
\hline F & 276.48 & 436.672 & 0.1857 & 0.025839901 & 152.54 \\
\hline I & 309.12 & 422.52 & -0.7753 & -0.000361189 & 2.08 \\
\hline
\end{tabular}

a)

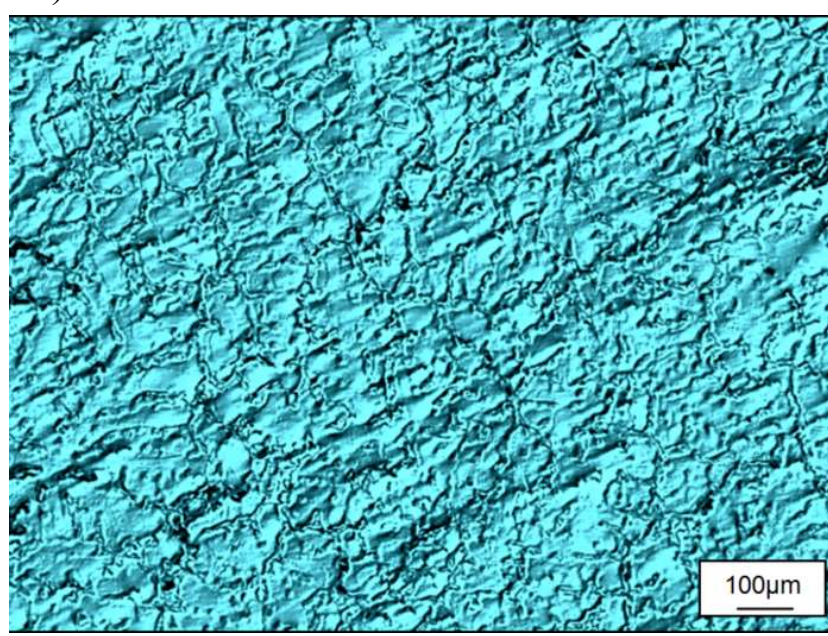

b)

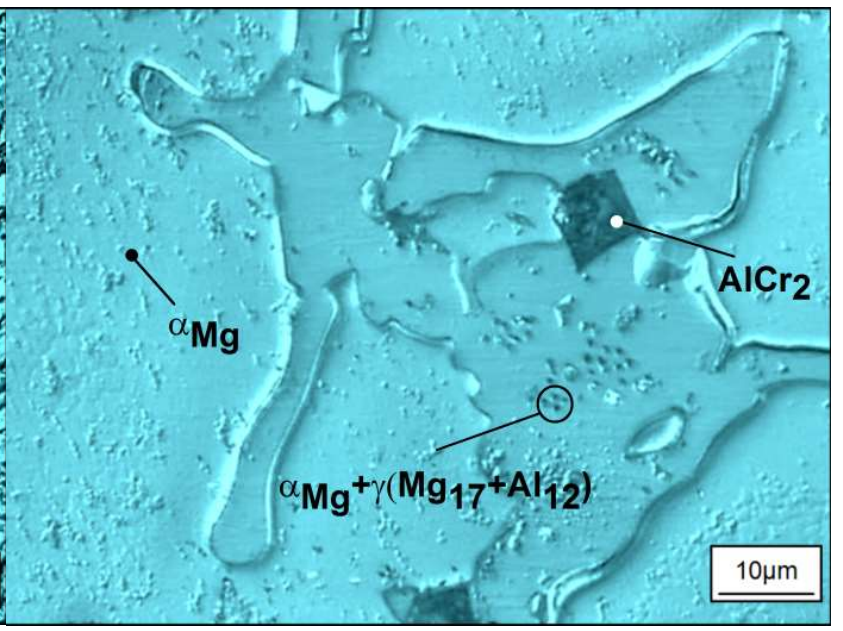

Fig. 2. Microstructure of alloy AZ91 with chromium additions cooling down in a ceramic TDA tester at room temperature (a,b) 
a)

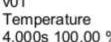

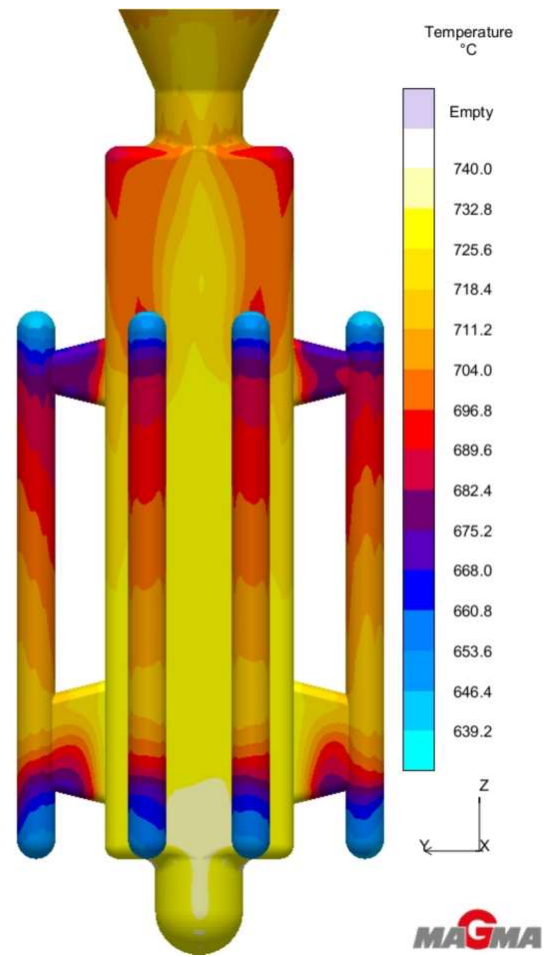

b)

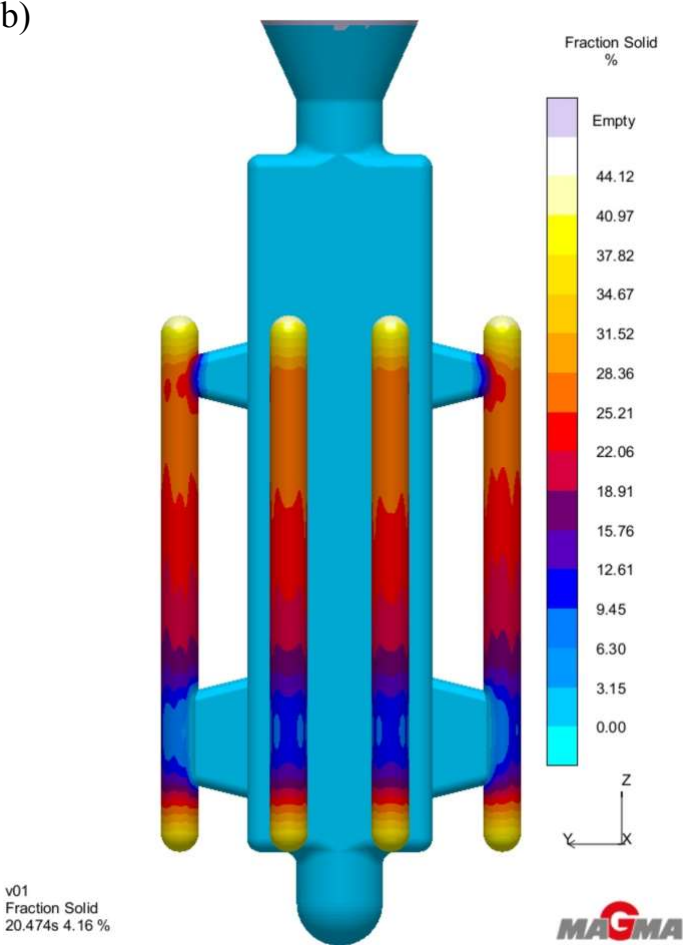

Fig. 3. Computer simulation results: a) casting temperature at the moment of casting alloy AZ91, b) amount of the solid phase in the AZ91 alloy casting after solidification time ca. $\tau=20.5 \mathrm{~s}$

a)

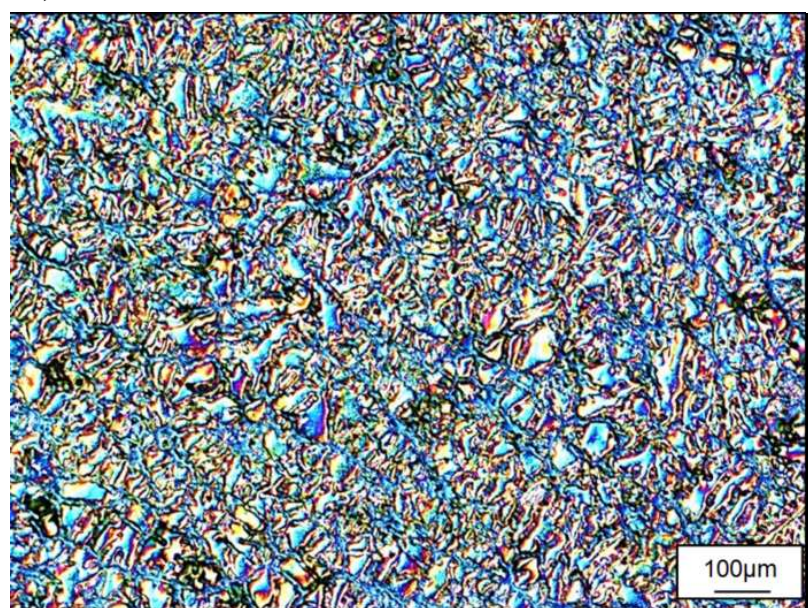

b)

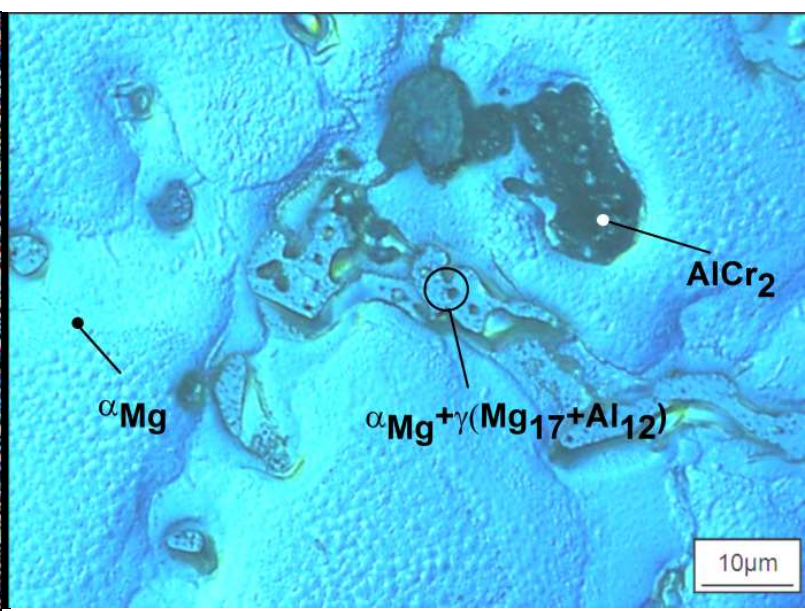

Fig. 4. Microstructure of alloy AZ91 with a chromium addition solidifying in an intensively cooled ceramic TDA tester $(\mathrm{a}, \mathrm{b})$

TABLE 4

Characteristic TDA points and their corresponding values: $t=f(\tau)$, $d t / d \tau=f^{\prime}(\tau), d^{2} t / d \tau^{2}=f^{\prime \prime}(\tau), \mathrm{Z} \approx\left(d^{2} t / d \tau^{2}\right) \cdot 10^{-3}$ for alloy AZ91 with a chromium addition, cooling in the TDA10C-PŁ tester, intensively cooled

\begin{tabular}{|c|c|c|c|c|c|}
\hline Point & $\begin{array}{c}\boldsymbol{\tau} \\
{[\mathbf{s}]}\end{array}$ & $\begin{array}{c}\boldsymbol{T} \\
{\left[{ }^{\circ} \mathbf{C}\right]}\end{array}$ & $\begin{array}{c}\boldsymbol{d} \boldsymbol{d} / \boldsymbol{d} \boldsymbol{\tau} \\
{\left[{ }^{\circ} \mathbf{C} / \mathbf{s}\right]}\end{array}$ & $\begin{array}{c}\boldsymbol{d}^{\mathbf{2}} \boldsymbol{t} / \boldsymbol{d} \boldsymbol{\tau}^{\mathbf{2}} \\
{\left[{ }^{\circ} \mathbf{C} / \mathbf{s}^{\mathbf{2}}\right]}\end{array}$ & $\begin{array}{c}\boldsymbol{Z} \approx \boldsymbol{d}^{\mathbf{2}} \boldsymbol{t} / \boldsymbol{d} \boldsymbol{\tau}^{\mathbf{2}} \cdot \mathbf{1 0}^{-\mathbf{3}} \\
{\left[{ }^{\circ} \mathbf{C} / \mathbf{s}^{\mathbf{2}}\right]}\end{array}$ \\
\hline A & 46.64 & 602.534 & -4.3977 & -0.45522 & 643.55 \\
\hline B & 56.88 & 580.497 & -0.4133 & 0.073501 & 139.52 \\
\hline D & 116.4 & 466.045 & -2.9247 & -0.00125 & -6.38 \\
\hline E & 116.4 & 466.045 & -2.9247 & -0.00125 & -6.38 \\
\hline F & 133.68 & 424.17 & -0.6376 & 0.028336 & 288.35 \\
\hline I & 146.48 & 397.739 & -2.7181 & -0.00072 & 20.55 \\
\hline
\end{tabular}

On the derivation curve $(d t / d \tau)$, points: $\mathrm{A}, \mathrm{D}$ and $\mathrm{E}$ determine the thermal effect of crystallization of phase $\alpha_{\mathrm{Mg}}$ in the volume of the tester; E-I determine the thermal effect of crystallization of eutectic $\alpha_{\mathrm{Mg}}+\gamma\left(\mathrm{Mg}_{17} \mathrm{Al}_{12}\right)$. After the metal overcooling below the equilibrium liquidus temperature, grains of phase $\alpha_{\mathrm{Mg}}$ nucleate and grow at the actual liquidus temperature $t_{A}$. The thermal effect of A-B-D includes the stage of intensive nucleation and growth of phase $\alpha_{\mathrm{Mg}}$, whose intensity decreases on the segment between points $\mathrm{D}$ and $\mathrm{E}$. At this stage, before the crystallization front of phase $\alpha_{\mathrm{Mg}}$ in the liquid metal, the $\mathrm{Al}$ concentration slowly increases, which, in consequence, leads to nucleation and growth of eutectic $\alpha_{\mathrm{Mg}}+\gamma\left(\mathrm{Mg}_{17} \mathrm{Al}_{12}\right)$. After the overcooling of the liquid alloy below the equilibrium tempera- 


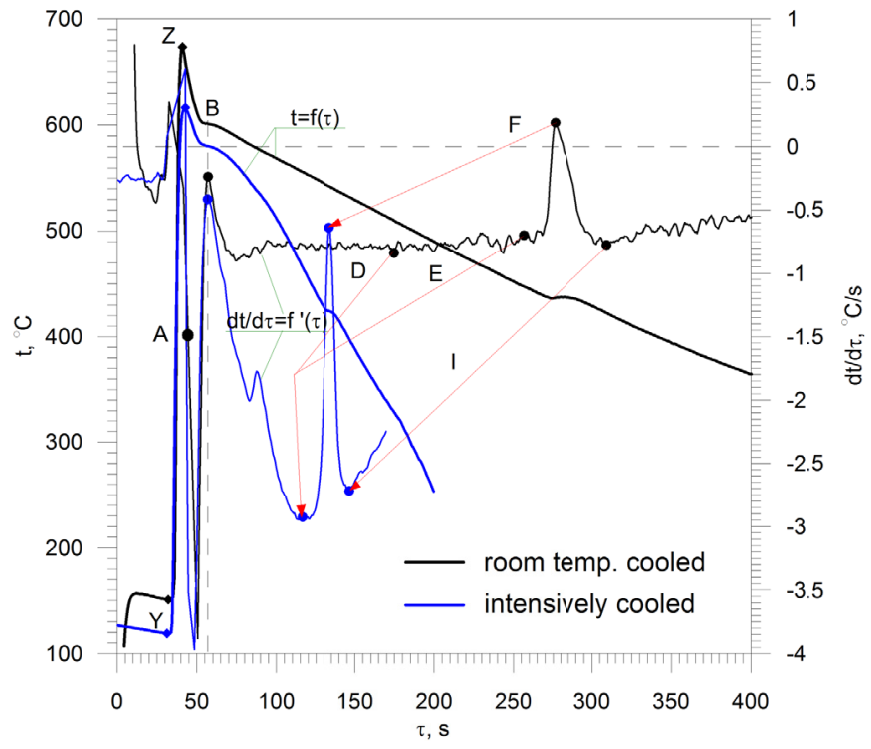

Fig. 5. TDA characteristics of alloy AZ91 with a chromium addition solidifying in a ceramic TDA tester at room temperature and intensively cooled

ture of the eutectic transformation, at the actual transformation temperature $t F$, we observe nucleation and growth of eutectic $\alpha_{\mathrm{Mg}}+\gamma\left(\mathrm{Mg}_{17} \mathrm{Al}_{12}\right)$. Alloy AZ91 with a chromium addition solidified in the volume of the TDA10C-PŁ tester in point I. Intensive cooling of alloy AZ91 with a chromium addition caused changes in the kinetics and dynamics of the thermal processes in respect of the alloy cooling at room temperature, which, in consequence, shortened the nucleation time of phase $\alpha_{\mathrm{Mg}}$ and caused the growth of eutectic $\alpha_{\mathrm{Mg}}+\gamma\left(\mathrm{Mg}_{17} \mathrm{Al}_{12}\right)$. The difference in the solidification time of the alloy in the volume of the tester between the alloy cooled at room temperature and the one intensively cooled equals $\Delta \tau_{\mathrm{A}-\mathrm{I}}=\tau_{\mathrm{A}-\mathrm{I} \text { room }}-\tau_{\mathrm{A} \text {-I intensively }}=(309.12$ $43.52)-(146.48-46.64)=165.76 \mathrm{~s}$, while the crystallization time of phase $\alpha_{\mathrm{Mg}}$ was shortened: $\Delta \tau_{\mathrm{A}-\mathrm{E}}=\tau_{\mathrm{A}-\mathrm{E} \text { room }}-\tau_{\mathrm{A}-\mathrm{E} \text { intensively }}=$ $(256.64-43.52)-(116.4-46.64)=142.86 \mathrm{~s}$, and the crystallization time of eutectic $\alpha_{\mathrm{Mg}}+\gamma\left(\mathrm{Mg}_{17} \mathrm{Al}_{12}\right)$ was shortened: $\Delta \tau_{\mathrm{E}-\mathrm{I}}=\tau_{\mathrm{E}-\mathrm{I}}$ room $-\tau_{\text {E-I intensively }}=(309.12-256.64)-(146.48-116.4)=22.4 \mathrm{~s}$.

\section{Mechanical properties of the examined alloys}

Figure 6 shows a diagram of the tensile strength UTS of the initial alloy AZ91, AZ91 with a chromium addition cooled at room temperature as well as alloy AZ91 with a chromium addition intensively cooled in a water solution of Polihartenol.

One can infer from the diagram shown in Figure 6 that the intensive cooling of the initial alloy AZ91 caused an increase of the tensile strength by $2 \mathrm{MPa}$, which constitutes an increase of the tensile strength of the casting by about $1.5 \%$. Introducing chromium as an alloy addition in the amount of $0.1 \%$ caused an increase of the tensile strength of the alloy with a chromium addition by $6 \mathrm{MPa}$ in respect of the initial alloy AZ91 cooled at room temperature, which constitutes an increase of the tensile strength of the casting by about $4.6 \%$. Additionally, intensive

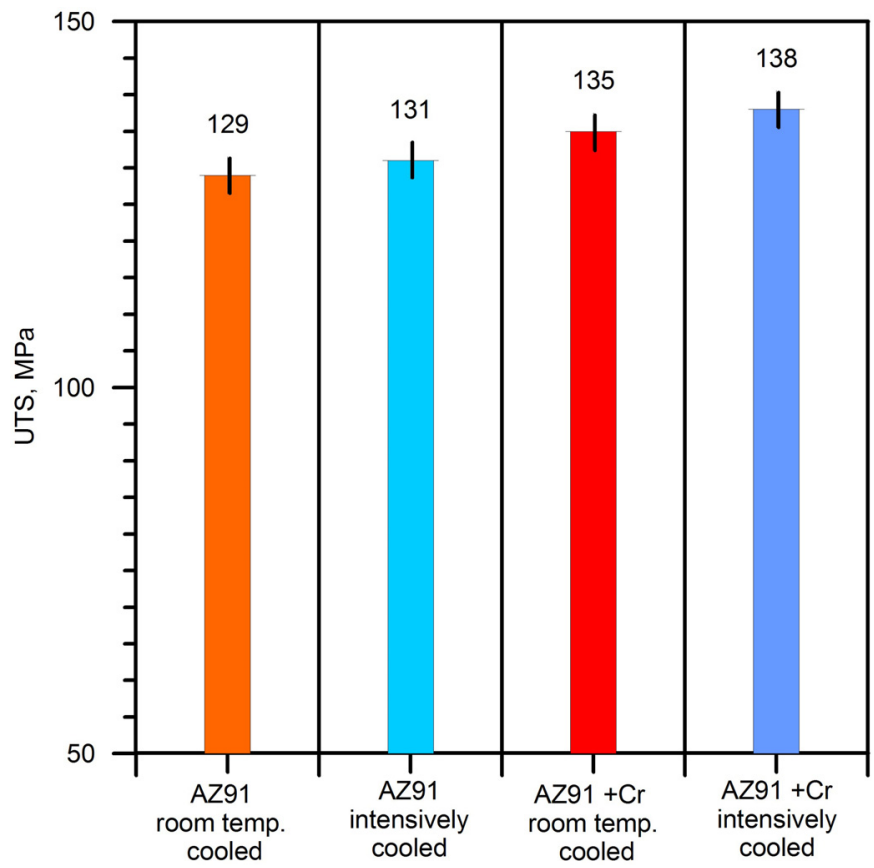

Fig. 6. Tensile strength UTS of alloy AZ91, AZ91 with a chromium addition solidifying at room temperature and intensively cooled

cooling of alloy AZ91 with a chromium addition increased the mechanical properties of the casting by $9 \mathrm{MPa}$, which constitutes an increase of the strength of the casting by $7 \%$ in respect of the initial alloy AZ91 cooled at room temperature.

Figure 7 shows a diagram of the elongation $\left(A_{5}\right)$ of the initial alloy AZ91, AZ91 with a chromium addition cooled at room temperature as well as of alloy AZ91 with a chromium addition intensively cooled in a water solution of Polihartenol.

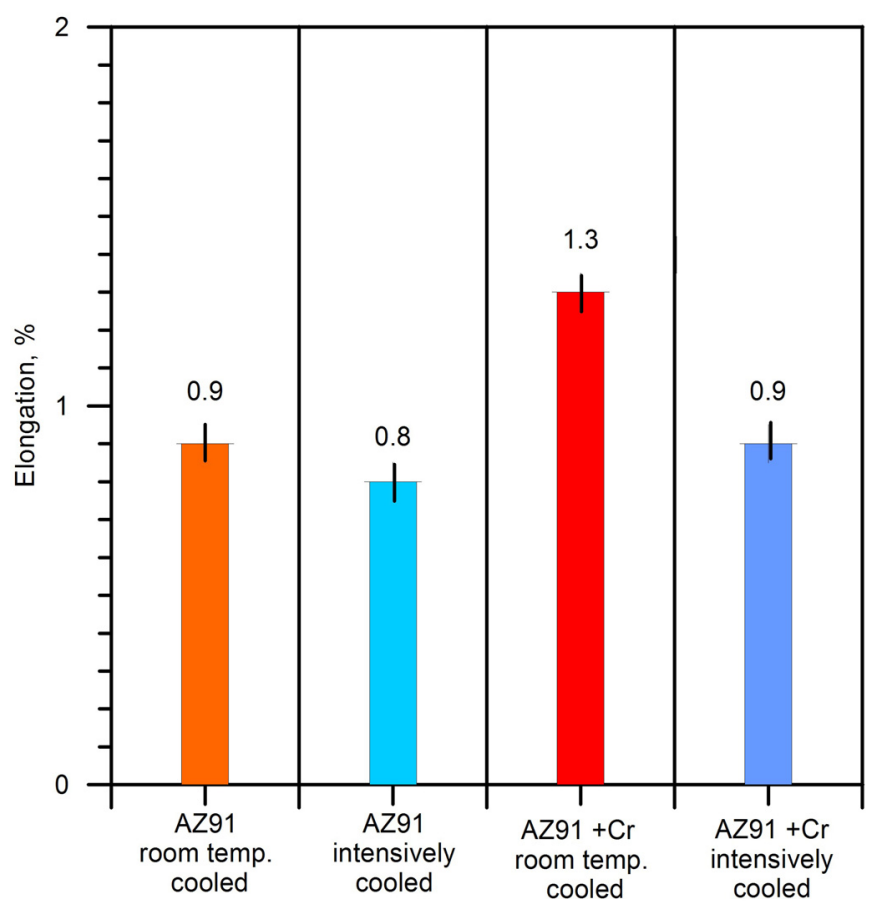

Fig. 7. Elongation $\left(A_{5}\right)$ of alloy AZ91, AZ91 with a chromium addition solidifying in a ceramic mould at room temperature and intensively cooled 
One can infer from the diagram presented in Figure 7 that intensive cooling of the initial alloy AZ91 caused a reduction of elongation $\mathrm{A}_{5}$ by $0.1 \%$, which consitutes a reduction of the elongation of the casting by about $12 \%$. Introducing a chromium addition and cooling the casting at ambienet temperature caused an increase of elongation $\mathrm{A}_{5}$ by $0.5 \%$, which constitutes an increase of the elongation value by $44 \%$. In turn, intensive cooling caused a reduction of elongation $\left(\mathrm{A}_{5}\right)$ to the value of $0.9 \%$.

Figure 8 shows the distribution of hardness $\mathrm{HB}$ of the initial alloy AZ91, AZ91 with a chromium addition cooled at room temperature as well as alloy AZ91 with a chromium addition intensively cooled in a water solution of Polihartenol.

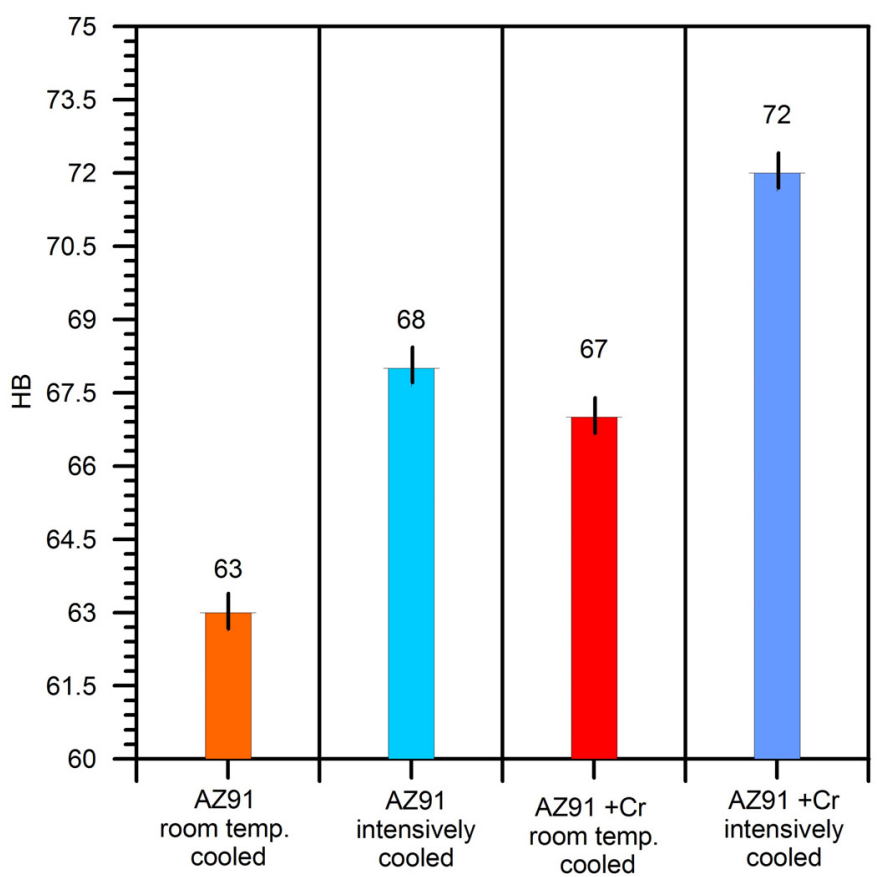

Fig. 8. Hardness HB of alloy AZ91, AZ91 with a chromium addition solidifying in a ceramic mould at room temperature and intensively cooled

One can infer from the diagram of hardness HB shown in Figure 8 that intensive cooling of the initial alloy AZ91 caused an increase of hardness HB by about $8 \%$. A similar effect was exerted by the addition of chromium to alloy AZ91. Intensive cooling of alloy AZ91 with a chromium addition increased hardness HB by $14 \%$ in respect of the initial alloy AZ91 cooled at room temperature.

\section{Conclusions}

One can infer from the performed research that the application of intensive cooling of alloy AZ91 with a chromium addition caused the following effects in respect of the initial alloy cooled at room temperature:

- a shortened time of primary crystallization of alloys with a magnesium matrix by about $50 \%$,

- a size reduction of primary phase $\alpha_{\mathrm{Mg}}$, of massive precipitations $\gamma\left(\mathrm{Mg}_{17} \mathrm{Al}_{12}\right)$ and of eutectic $\alpha+\gamma\left(\mathrm{Mg}_{17} \mathrm{Al}_{12}\right)$,
- $\quad$ an increase of the strength properties UTS by about $7 \%$,

- an increase of hardness HB by about $14 \%$,

- $\quad$ no effect on the value of unit elongation $\left(\mathrm{A}_{5}\right)$.

\section{Acknowledgements}

This work was realized within the frames of Project PBS I, financed by the National Centre for Research and Development. Poland. Project ID: 178739. Project implemented in 2013-2015.

\section{REFERENCES}

[1] K.U. Kainer, Magnesium: Proceedings of the 7th International Conference on Magnesium Alloys and Their Applications. 2007 Wiley-VCH, Weinheim.

[2] A. Boby, K.K. Ravikumar, U.T.S. Pillai, B.C. Pai, Proc. Eng. 55, 98-102 (2013).

[3] Y. Chen, H. Liu, R. Ye, G. Liu, Mater. Sci. Eng. A 587, 262-267 (2013).

[4] X. Ai, G. Quan, J. Open Mater. Sci. 6, 6-13 (2012).

[5] S. Candan, M. Unal, E. Koc, Y. Turen, E. Candan, J. Alloys Comp. 509, 1958-1963 (2011)

[6] Y. Turen, Mate. Des. 49, 1009-1015 (2013).

[7] J. Lelito, P.L. Żak, A.L. Greer, J.S. Suchy, W.K. Krajewski, B. Gracz, M. Szucki, A.A. Shirzadi, Composites Part B - Engineering 43, 3306-3309 (2012).

[8] J. Lelito, P. Żak, J.S. Suchy, W. Krajewski, A.L. Greer, P. Darłak, China Foundry 8, 101-106 (2011).

[9] W.K. Krajewski, J. Lelito, J.S. Suchy, P. Schumacher, Arch. Metall. Mater. 54, 335-338 (2009).

[10] A. Grzybowska, K.N. Braszczyńska-Malik, Arch. Found. Eng. 11 (2), 23-26 (2012).

[11] Z. Zhenwei, T. Xinying, Z. Guorong, L. Jinfeng, G. Jiwei, Rare Metall. Mater. Eng. 43 (4), 791-795 (2014).

[12] C. Rapiejko, B. Pisarek, T. Pacyniak, Arch. Metall. Mater. 59 (2), 761-765 (2014)

[13] D. Mirković, R. Schmid-Fetzer, Metall. Mater. Trans. A 40A, 974-81 (2009).

[14] R. Władysiak, A. Kozuń, Arch. Found. Eng. 15 (1), 113-118 (2015).

[15] C. Rapiejko, B. Pisarek, T. Pacyniak, Arch. Found. Eng. 14 (1), 97-102 (2014).

[16] J. Gabriel, ZGV-Zentrale Fuer Gussverwendung 21 (1), 4-10 (1996).

[17] Ch. Liesner, R. Gerke-Cantow, ZGV- Zentrale Fuer Gussverwendung 27 (2), 41-44 (2002).

[18] http://www.aeromet.co.uk/casting-division/index.html

[19] S. Pietrowski, C. Rapiejko, Arch. Found. Eng. 11 (3), 177-186 (2011).

[20] C. Rapiejko, B. Pisarek, E. Czekaj, T. Pacyniak, Arch. Metall. Mater. 59 (4), 1449-1455 (2014).

[21] A. Maltais, D. Dube, M. Fiset, G. Laroche, S. Tugeon, Mater. Char. 52, 103-119 (2004). 